\section{Antiallergika: Metabolit steigert die Wirksamkeit}

D esloratadin $\left(\right.$ Aerius $^{\circledR}$ ) ist der aktive Metabolit des Loratadins, repräsentiert aber nach den Worten von U. Borchard (Düsseldorf) praktisch eine neue Klasse von Antiallergika:

— Es bindet erheblich stärker an den Histamin-H1-Rezeptor als andere Antiallergika. So sind nach sechs Stunden noch fast zwei Drittel des Desloratadins an den Rezeptor gebunden, während etwa Cetirizin nach zwei Stunden bereits zur Hälfte wieder abdissoziiert ist.

— Durch Wegfall der Metabolisierung durch Enzyme des CytochromP450-Systems in der Leber besteht auch kein Risiko von Wechselwirkungen mit anderen Medikamen- ten. Desloratadin kann deshalb bei Bedarf auch höher dosiert werden.

- Weil Desloratadin um den Faktor 500 hydrophiler ist als die Muttersubstanz, kann es nicht die BlutHirn-Schranke penetrieren und am zerebralen H1-Rezeptor wirken.

- Neben der anti-histaminergen weist Desloratadin auch anti-entzündliche und anti-obstruktive Aktivität auf.

In einer doppelblinden, multizentrischen Studie, die R. Hein (München) vorstellte, erhielten 190 Patienten mit chronischer idiopathischer Urtikaria über sechs Wochen entweder täglich $5 \mathrm{mg}$ Desloratadin oder Plazebo. Während der Pruritus-Score als primärer Endpunkt in der Plazebogruppe um
$21,5 \%$ reduziert wurde, war der Rückgang unter Verum mit $56 \%$ mehr als doppelt so hoch. Die Anzahl der Quaddeln nahm unter Plazebo um 16\%, unter Desloratadin hingegen um $48 \%$ ab. Bei der Größe der Quaddeln lagen die entsprechenden Werte bei 17 bzw. $50 \%$. Schlaf und Alltagsaktivitäten und damit auch die Lebensqualität der Patienten wurden durch Desloratadin signifikant gebessert.

Patienten, die während der Studien nicht auf 5 mg Desloratadin angesprochen hatten, profitierten von der Nebenwirkungsfreiheit der Substanz auch bei höheren Dosierungen: Sie erhielten nach Studienende $10 \mathrm{mg}$ und wurden dadurch weitgehend symptomfrei. $\quad j f g$

Presse-Symposium „AERIUS ${ }^{\circledR}$ - signifikante Überlegenheit bei der Behandlung der Urtikaria“, Rottach-Egern, 2001. Veranstalter: Essex Pharma.

\title{
Neurodermitis: topische nicht-steroidale Alternative vor der Einführung
}

Dimate ie Prävalenz des atopischen Ekzems hat sich in den letzten 30 Jahren in den westlichen Industrieländern nahezu verdreifacht. Unter dieser, die Lebensqualität beeinträchtigenden chronischentzündlichen Erkrankung leiden ca. 2,5\% der Erwachsen und 10-15\% der Kinder. Die wachsende Dimension des Problems und dessen sozio-ökonomische Folgekosten bestärkten den Ruf nach neuen, effektiveren Medikamenten zur Bekämpfung dieses Übels.

Mit Tacrolimus (Protopic ${ }^{\circledR}$ ), dem ersten Wirkstoff einer neuen Klasse nicht-steroidaler topischer Immunmodulatoren, steht erstmals seit 50 Jahren ein Agens vor der Einführung, das aufgrund seiner Effektivität und guten Verträglichkeit bald zum Standardregime in der Behandlung des atopischen Ekzems avancieren könnte, erklärte T. Ruzicka (Düsseldorf). Dafür sprechen eine Reihe von Vorteilen: Anders als topische Kortikosteroide führt die Salbe mit dem neuen Wirkstoff nicht zu Hautatrophie und bewirkt bereits nach drei Tagen ein Abklingen des Pruritus um $50 \%$, nach drei Wochen um $90 \%$. Der Wirkstoff setzt dabei gezielt an den Ursachen der Erkrankung auf immunologischer Ebene an.

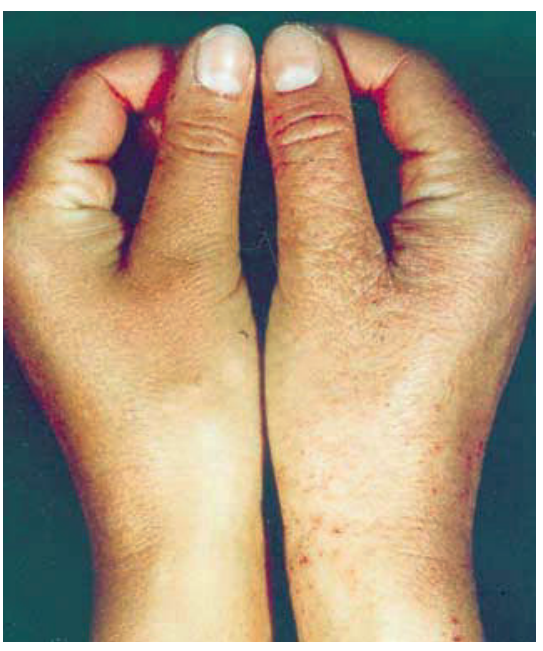

Etwa 2,5\% der Erwachsenen und 10-15\% der Kinder leiden unter atopischem Ekzem.
Nach Untersuchungen von S. Romagnani, Florenz, wirkt TacrolimusSalbe inhibitorisch auf Zytokine vom TH1- und TH2-Typ, die für die chronische Ausprägung des atopischen Ekzems bzw. als auslösende Faktoren für die Entzündungsreaktion verantwortlich gemacht werden. Tacrolimus hat sich Untersuchungen in seinem Institut zufolge als besonders effektiv in der Unterdrückung TH1-vermittelter Inflammationen, superinfiziert mit Pilzen und Bakterien, erwiesen. Sein großes Potenzial in der Behandlung des atopischen Ekzems wurde in klinischen Studien mit über 10.000 eingeschlossenen Patienten bestätigt.

Wie Fujisawa Europe mitteilte, verabschiedete der CPMP am 22. Oktober 2001 eine positive Empfehlung zur Zulassung von Tacrolimus in Europa (Salbe in der Konzentration von $0,1 \%$ für Erwachsene, $0,03 \%$ für Kinder). Mit der Einführung in Deutschland ist im ersten Quartal $2002 \mathrm{zu}$ rechnen.

Pressegespräch „Tacrolimus ointment - a new era in the treatment of atopic eczema“, München, 2001. Veranstalter: Fujisawa Pharmaceutical 